\title{
A Concise Review of Pelvic Radiation Therapy (RT) for Rectal Cancer with Synchronous Liver Metastases
}

\author{
Omer Sager (D), Ferrat Dincoglan, Selcuk Demiral, Bora Uysal, Hakan Gamsiz, \\ Bahar Dirican, and Murat Beyzadeoglu \\ Department of Radiation Oncology, University of Health Sciences, Gulhane Medical Faculty, Ankara, Turkey \\ Correspondence should be addressed to Omer Sager; omersager@gmail.com
}

Received 30 November 2018; Accepted 3 April 2019; Published 21 April 2019

Academic Editor: C. H. Yip

Copyright (c) 2019 Omer Sager et al. This is an open access article distributed under the Creative Commons Attribution License, which permits unrestricted use, distribution, and reproduction in any medium, provided the original work is properly cited.

\begin{abstract}
Background and Objective. Colorectal cancer is a major health concern as a very common cancer and a leading cause of cancerrelated mortality worldwide. The liver is a very common site of metastatic spread for colorectal cancers, and, while nearly half of the patients develop metastases during the course of their disease, synchronous liver metastases are detected in $15 \%$ to $25 \%$ of cases. There is no standardized treatment in this setting and no consensus exists on optimal sequencing of multimodality management for rectal cancer with synchronous liver metastases. Methods. Herein, we review the use of pelvic radiation therapy (RT) as part of potentially curative or palliative management of rectal cancer with synchronous liver metastases. Results. There is accumulating evidence on the utility of pelvic RT for facilitating subsequent surgery, improving local tumor control, and achieving palliation of symptoms in patients with stage IV rectal cancer. Introduction of superior imaging capabilities and contemporary RT approaches such as Intensity Modulated Radiation Therapy (IMRT) and Image Guided Radiation Therapy (IGRT) offer improved precision and toxicity profile of radiation delivery in the modern era. Conclusion. Even in the setting of stage IV rectal cancer with synchronous liver metastases, there may be potential for extended survival and cure by aggressive management of primary tumor and metastases in selected patients. Despite lack of consensus on sequencing of treatment modalities, pelvic RT may serve as a critical component of multidisciplinary management. Resectability of primary rectal tumor and liver metastases, patient preferences, comorbidities, symptomatology, and logistical issues should be thoroughly considered in decision making for optimal management of patients.
\end{abstract}

\section{Background and Introduction}

Colorectal cancer is a major health concern as a very common cancer and a leading cause of cancer-related mortality worldwide [1-4]. Cancers of the rectum account for a considerable proportion of all large intestine cancers and are typically included within the group of colorectal cancers in epidemiological studies [5]. The liver is a very common site of metastatic spread for colorectal cancers, and, while nearly half of the patients develop metastases during the course of their disease, synchronous liver metastases are detected in $15 \%$ to $25 \%$ of cases [6-12]. With ever-increasing advances in both surgical and clinical oncology disciplines, multimodality management has substantially improved outcomes of rectal cancer with oligometastases. If feasible, surgical removal of the primary rectal tumor along with resection/ablation of liver metastases as a potentially curative therapeutic approach has been shown to achieve survival rates exceeding $70 \%$ at 5 years for selected patients with limited disease burden [1347].

The role of radiation therapy (RT) in the management of nonmetastatic locally advanced rectal cancers is well established; however, its utility in the setting of synchronous liver metastases needs elucidation. Herein, we address the utility of pelvic RT as part of potentially curative or palliative management of rectal cancer with synchronous liver metastases in light of the literature.

\section{Rationale for Pelvic RT in the Setting of Rectal Cancer with Liver Metastases}

The utility of RT has been well established in nonmetastatic locally advanced rectal cancer, and preoperative sequencing 
of pelvic irradiation rather than postoperative administration has been shown to reduce the risk of local recurrence and cancer related mortality [48-50]. In terms of dose and fractionation for preoperative pelvic irradiation, 2 main RT schemes include short course RT (SCRT) to deliver a total radiation dose of 25 Gy with 5 daily treatment fractions of $5 \mathrm{~Gy}$ each over 1 week and long course RT (LCRT) to deliver a total radiation dose of 45-50.4 Gy (with or without an additional boost of 5.4 Gy delivered in 3 fractions if circumferential resection margin is threatened) over 5 to 6 weeks with conventional fractionation (1.8-2 Gy per each fraction). While assessment of local failure, disease free survival (DFS), overall survival (OS), sphincter preservation, late toxicity, and quality of life revealed comparable outcomes with both preoperative RT approaches in several studies, practice patterns vary widely around the globe [5158]. Surgery with total mesorectal excision (TME) has been traditionally scheduled within 1 week (immediate surgery) or 6 to 8 weeks after completion of SCRT or LCRT, respectively $[48,49,59]$. However, considering the increased pathological response rates achieved with a longer time interval between preoperative RT and surgery, delayed rather than immediate surgery after preoperative SCRT has been suggested as a viable therapeutic approach to improve treatment outcomes [60-69]. While incorporation of RT in multimodality treatment of nonmetastatic rectal cancers is widely accepted, its utility for management of rectal cancer is debated in the setting of synchronously detected liver metastases.

Given the increased life expectancy of patients with metastatic stage IV rectal cancer treated in the modern era using more effective local and systemic therapies, addressing of the primary disease becomes more critical to improve patient comfort and quality of life with contemporary RT techniques allowing improved toxicity profile. Indeed, $7 \%$ of the study population consisted of patients with stage IV rectal cancer in the landmark Dutch trial assessing preoperative RT followed by TME, and reported rates of 2-year local recurrence were $10.1 \%$ and $23.8 \%$ for patients treated with or without preoperative RT, respectively [70]. Other studies focusing on management of stage IV rectal cancer have also incorporated RT as part of multimodality management with several purposes including symptomatic palliation of symptoms, local control of primary disease, and facilitating subsequent TME surgery [71-87].

Several studies investigating the omission of RT in the setting of nonmetastatic or metastatic disease consistently reported inferior outcomes, substantiating the utility of RT in multimodality management of rectal cancer [88-91]. Moreover, in the setting of metastatic rectal cancer, improved primary tumor control by use of local therapy has been associated with improved prognosis and survival as well [92, 93].

\section{Review of Studies Including Pelvic RT with Palliative Intent}

Selected series incorporating pelvic RT in multimodality management of stage IV rectal cancer with liver metastases (with or without other distant metastases) as a palliative therapeutic strategy are summarized in Table 1.

Pelvic RT achieves effective palliation of symptoms due to primary tumor in stage IV rectal cancer. Two reviews focusing on studies conducted in different time periods (1949-1999 and 2011-2016) confirmed the palliative efficacy of RT for management of primary rectal tumor related symptoms $[94,95]$.

In the systematic review by Cameron et al. based on 27 studies, pooled overall symptomatic response rate was $75 \%$, while response rates were $78 \%, 81 \%, 71 \%$, and $72 \%$ for symptoms of pain, bleeding and discharge, mass effect, and other pelvic symptoms, respectively [94].

Buwenge et al. reviewed more recently published series and reported response rates of $79 \%, 87 \%$, and $78 \%$ for symptoms of pain, bleeding, and obstruction, respectively [95]. In addition to 2 retrospective and 2 prospective series in our review (Table 1), these 2 reviews with different study periods revealed effective palliation of pelvic symptoms by using RT [94, 95]. Similar response rates in both earlier and more recent RT series suggest that the palliative efficacy of RT may not be neglected in the modern era and persists despite the availability of newer effective systemic treatments.

\section{Pelvic RT as Part of Potentially Curative Multimodality Management of Rectal Cancer with Synchronously Detected Liver Metastases}

Synchronous liver metastases have been variably defined in the literature. Most common definition includes metastases detected at or before diagnosis of primary rectal cancer; however, metastases detected within 3 to 6 months of diagnosis have also been included in the "synchronous" group in several studies [96-101]. Compared to metachronous liver metastases, synchronously detected liver metastases may be associated with poorer prognosis and survival [96, 102104]. Even in this setting, there remains the potential for cure with multimodality management. Outcomes of selected series incorporating RT in multimodality management of rectal cancer with synchronously detected liver metastases are summarized in Table 2.

Despite heterogeneity in patient and treatment characteristics in these studies, several conclusions may be drawn.

Although with a very limited sample size, the study by Shin et al. using SCRT in multimodality management reported a high rate (84\%) of R0 resection with no LR during the follow-up period [73].

In the study by Fossum et al. including 93 patients, LR was not observed in patients receiving neoadjuvant $\mathrm{RT}$, and omission of neoadjuvant RT was associated with development of subsequent LR [91].

Overall, outcomes of 8 retrospective and 4 prospective studies reveal that pelvic RT may serve as a critical component of multidisciplinary management (Table 2). Contemporary RT techniques including Intensity Modulated Radiation Therapy (IMRT) and Image Guided Radiation Therapy (IGRT) along with timely management of radiation 


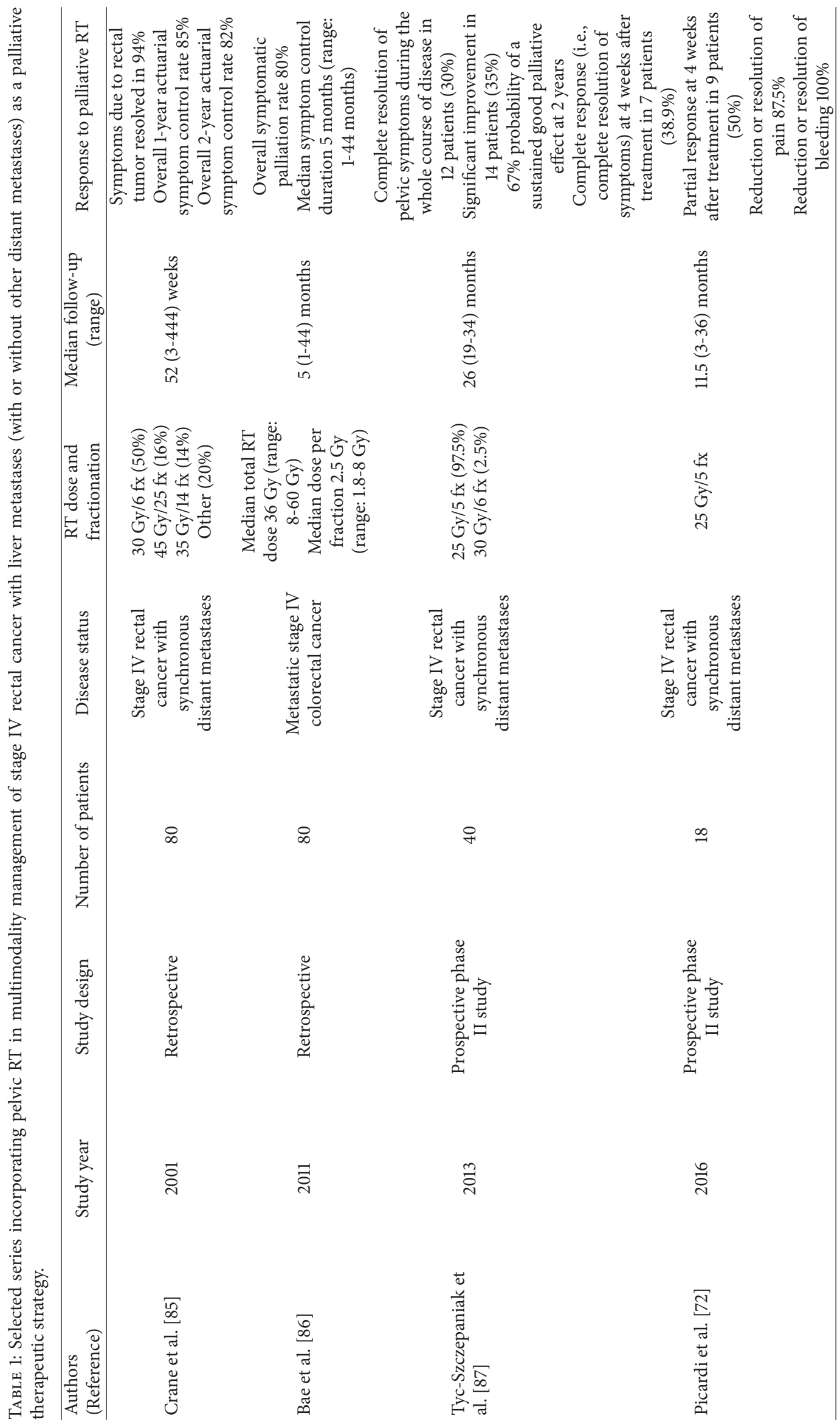




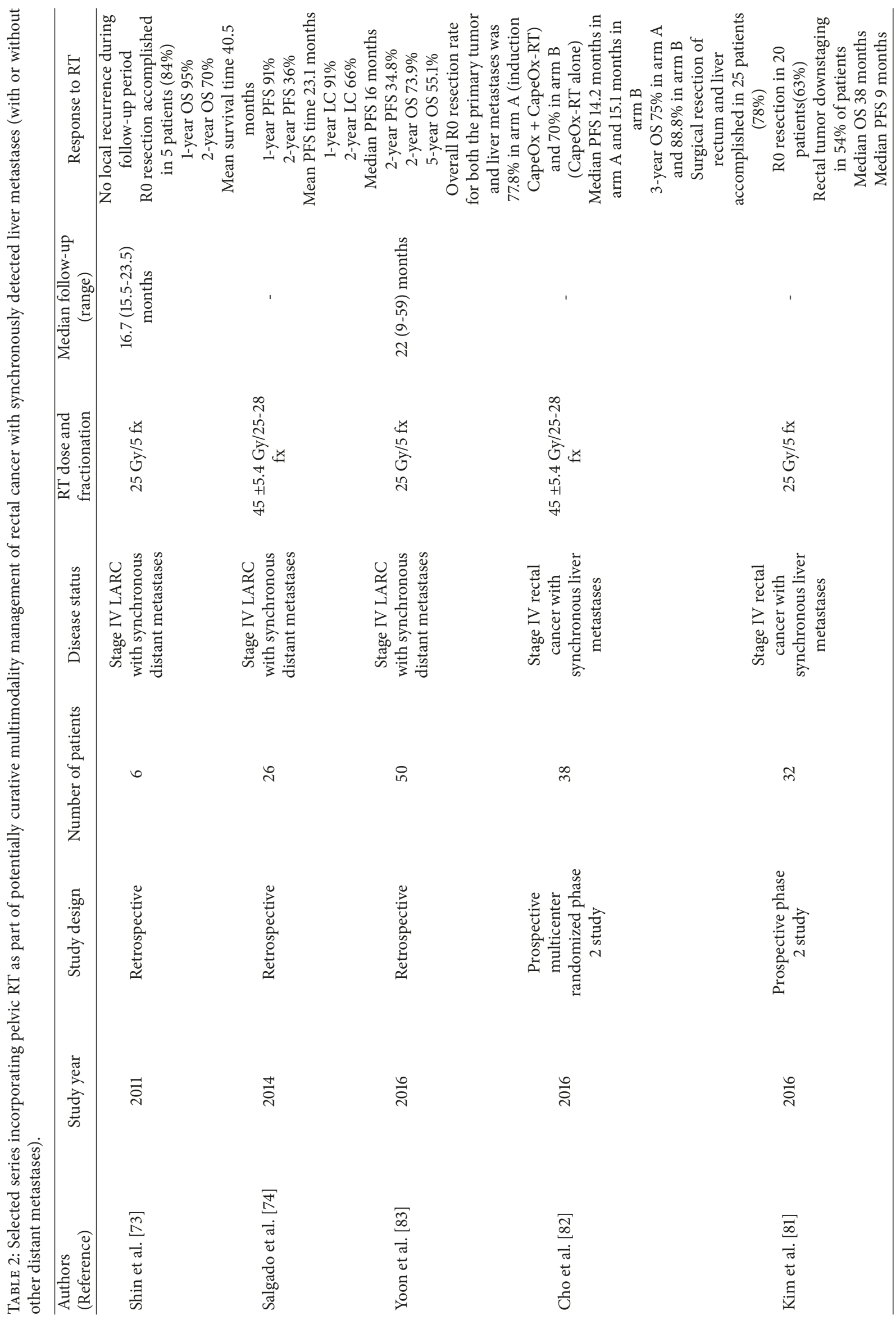




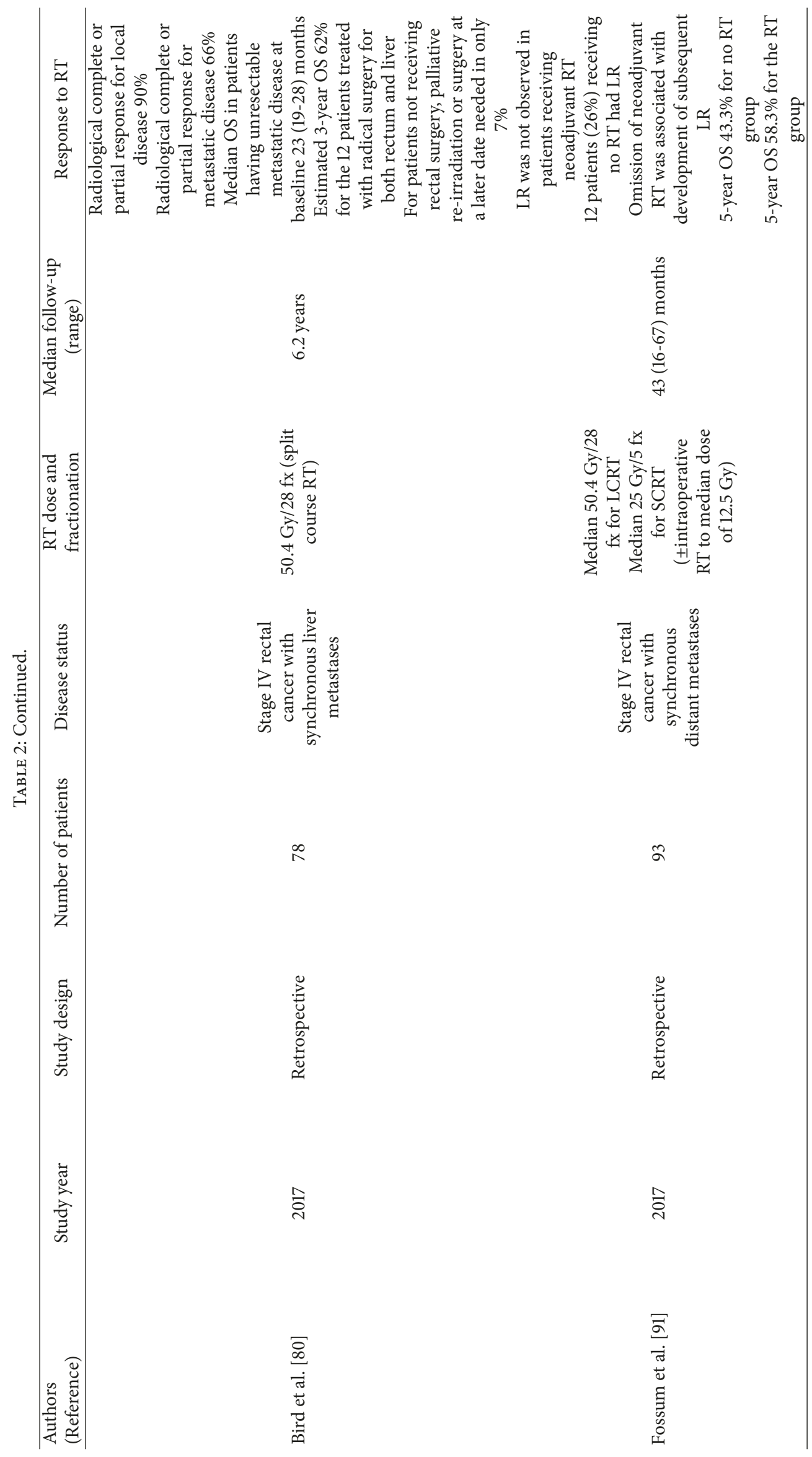




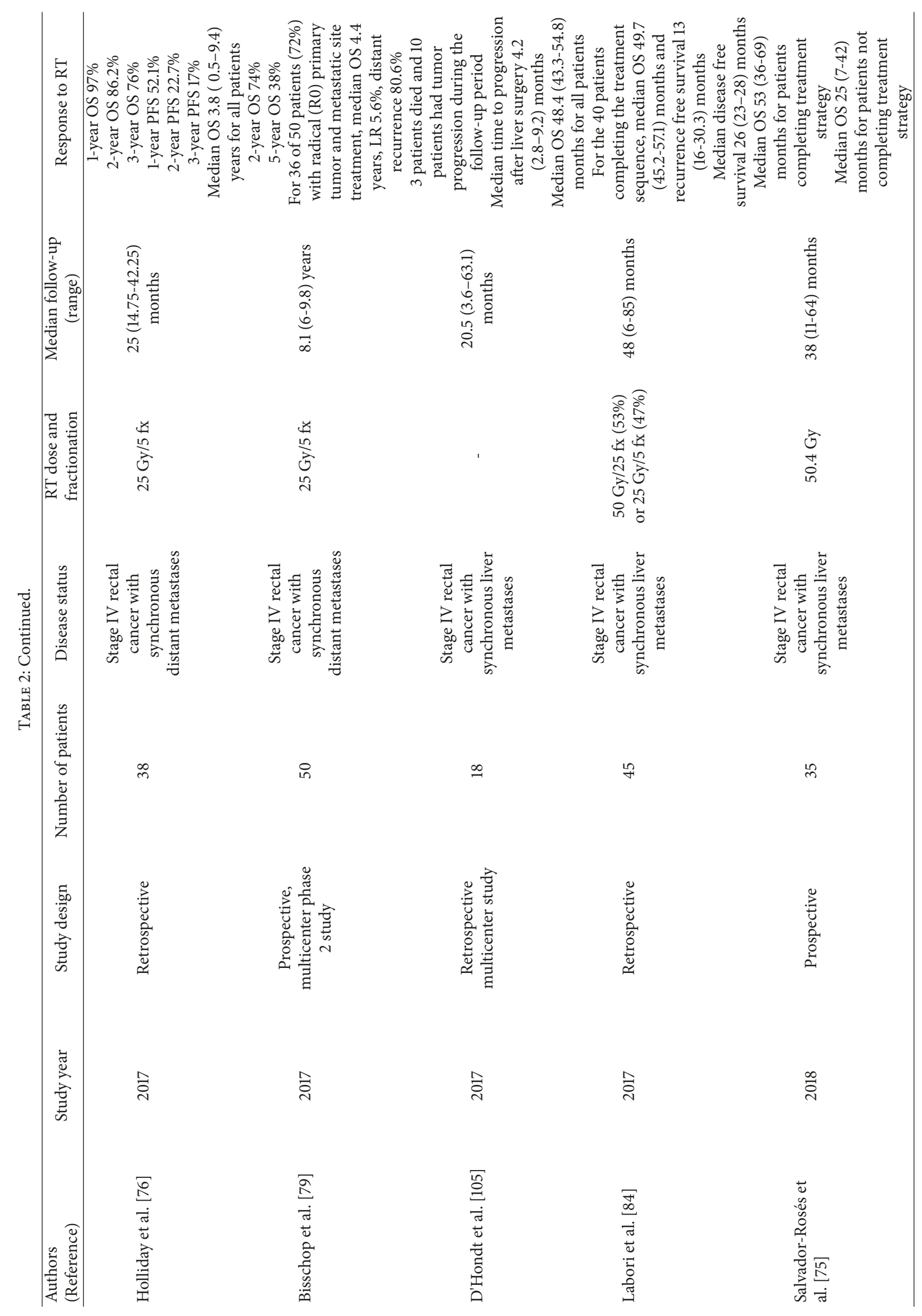


induced toxicity by use of nutritional supplementation may improve patient compliance and quality of life [106].

\section{Conclusion}

Even in the setting of stage IV rectal cancer with synchronous liver metastases, there may be potential for extended survival and cure by aggressive management of primary tumor and metastases in selected patients. Despite lack of consensus on sequencing of treatment modalities, pelvic RT may serve as a critical component of multidisciplinary management. Resectability of primary rectal tumor and liver metastases, patient preferences, comorbidities, symptomatology, and logistical issues should be thoroughly considered in decision making for optimal management of patients. Similar response rates in earlier and more recent palliative RT series suggest that the palliative efficacy of RT may not be neglected in the modern era and persists despite the availability of newer effective systemic treatments.

Given the increased life expectancy of patients with rectal cancer and synchronous liver metastases, addressing of the primary tumor with pelvic RT may have utility as part of potentially curative management. SCRT may be preferred in this setting to avoid delaying of systemic treatment, and improving distant as well as local control may be attempted by use of intensified chemoradiotherapy regimens. Modern RT techniques offer excellent precision and accuracy with an improved toxicity profile.

Backdating of liver surgery to be performed in the interval between RT and rectal surgery may be a viable therapeutic approach to shorten the overall treatment time and liver first strategies may be thoroughly investigated to avoid progression of liver metastases during the disease course. Intensification of systemic treatment with or without biological agents, immunotherapy, optimal dose and fractionation for RT, optimal sequencing, and combination of treatment modalities warrant further extensive research.

\section{Conflicts of Interest}

The authors declare no conflicts of interest, financial or otherwise.

\section{Authors' Contributions}

Omer Sager contributed to study conception and design, data collection, data analysis and interpretation, and manuscript drafting. Ferrat Dincoglan took part in the study conception and design, data collection, and manuscript drafting. Selcuk Demiral participated in study conception and design, data collection, and data analysis and interpretation. Bora Uysal partook in data collection, data analysis and interpretation, and manuscript drafting. Hakan Gamsiz contributed to study conception and design, data analysis and interpretation, and manuscript drafting. Bahar Dirican took part in study conception and design, data analysis and interpretation, and manuscript drafting. Murat Beyzadeoglu participated in study conception and design, data collection, and data analysis and interpretation.

\section{References}

[1] F. Bray, J. Ferlay, I. Soerjomataram et al., "Global cancer statistics 2018: GLOBOCAN estimates of incidence and mortality worldwide for 36 cancers in 185 countries," CA: A Cancer Journal for Clinicians, vol. 68, no. 6, pp. 394-424, 2018.

[2] R. L. Siegel, K. D. Miller, S. A. Fedewa et al., "Colorectal cancer statistics," CA: A Cancer Journal for Clinicians, vol. 67, no. 3, pp. 177-193, 2017.

[3] A. Bhandari, M. Woodhouse, and S. Gupta, "Colorectal cancer is a leading cause of cancer incidence and mortality among adults younger than 50 years in the USA: a SEER-based analysis with comparison to other young-onset cancers," Journal of Investigative Medicine, vol. 65, no. 2, pp. 311-315, 2017.

[4] B. Ansa, S. Coughlin, E. Alema-Mensah, and S. Smith, "Evaluation of Colorectal Cancer Incidence Trends in the United States (2000-2014)," Journal of Clinical Medicine, vol. 7, no. 2, p. 22, 2018.

[5] N. F. Aykan, S. Yalcin, N. S. Turhal et al., "Epidemiology of colorectal cancer in Turkey: A cross-sectional disease registry study (A Turkish Oncology Group trial)," The Turkish Journal of Gastroenterology, vol. 26, no. 2, pp. 145-153, 2015.

[6] S. Manfredi, C. Lepage, C. Hatem, O. Coatmeur, J. Faivre, and A.-M. Bouvier, "Epidemiology and management of liver metastases from colorectal cancer," Annals of Surgery, vol. 244, no. 2, pp. 254-259, 2006.

[7] M. H. Al Bandar and N. K. Kim, "Current status and future perspectives on treatment of liver metastasis in colorectal cancer (Review)," Oncology Reports, vol. 37, no. 5, pp. 25532564, 2017.

[8] F. Aigner, J. Pratschke, and M. Schmelzle, "Oligometastatic disease in colorectal cancer - how to proceed?" Visceral Medicine, vol. 33, no. 1, pp. 23-28, 2017.

[9] B. K. Edwards, E. Ward, B. A. Kohler et al., "Annual report to the nation on the status of cancer, 1975-2006, featuring colorectal cancer trends and impact of interventions (risk factors, screening, and treatment) to reduce future rates," Cancer, vol. 116, no. 3, pp. 544-573, 2010.

[10] D. C. McMillan and C. S. McArdle, "Epidemiology of colorectal liver metastases," Surgical Oncology, vol. 16, no. 1, pp. 3-5, 2007.

[11] M. M. Borner, "Neoadjuvant chemotherapy for unresectable liver metastases of colorectal cancer - Too good to be true? Editorial," Annals of Oncology, vol. 10, no. 6, pp. 623-626, 1999.

[12] P. M. Lykoudis, D. O’Reilly, K. Nastos, and G. Fusai, "Systematic review of surgical management of synchronous colorectal liver metastases," British Journal of Surgery, vol. 101, no. 6, pp. 605612, 2014.

[13] V. P. Khatri, N. J. Petrelli, and J. Belghiti, "Extending the frontiers of surgical therapy for hepatic colorectal metastases: Is there a limit?" Journal of Clinical Oncology, vol. 23, no. 33, pp. 84908499, 2005.

[14] M. Hosseinali Khani, L. Påhlman, and K. Smedh, "Treatment strategies for patients with stage IV rectal cancer: A report from the Swedish Rectal Cancer Registry," European Journal of Cancer, vol. 48, no. 11, pp. 1616-1623, 2012.

[15] C. Pinto, S. Pini, F. Di Fabio et al., "Treatment strategy for rectal cancer with synchronous metastasis: 65 consecutive italian cases from the bologna multidisciplinary rectal cancer group," Oncology, vol. 86, no. 3, pp. 135-142, 2014. 
[16] L. R. Zarour, S. Anand, K. G. Billingsley et al., "Colorectal cancer liver metastasis: evolving paradigms and future directions," Cellular and Molecular Gastroenterology and Hepatology, vol. 3, no. 2, pp. 163-173, 2017.

[17] E. P. Misiakos, N. P. Karidis, and G. Kouraklis, "Current treatment for colorectal liver metastases," World Journal of Gastroenterology, vol. 17, no. 36, pp. 4067-4075, 2011.

[18] J.-K. Lin, L.-K. Lee, W.-S. Chen et al., "Concurrent chemoradiotherapy followed by metastasectomy converts to survival benefit in stage IV rectum cancer," Journal of Gastrointestinal Surgery, vol. 16, no. 10, pp. 1888-1896, 2012.

[19] S. Kopetz, G. J. Chang, M. J. Overman et al., "Improved survival in metastatic colorectal cancer is associated with adoption of hepatic resection and improved chemotherapy," Journal of Clinical Oncology, vol. 27, no. 22, pp. 3677-3683, 2009.

[20] D. J. Gallagher and N. Kemeny, "Metastatic colorectal cancer: from improved survival to potential cure," Oncology, vol. 78, no. 3-4, pp. 237-248, 2010.

[21] A. de Rosa, D. Gomez, S. Hossaini et al., "Stage IV colorectal cancer: Outcomes following the liver-first approach," Journal of Surgical Oncology, vol. 108, no. 7, pp. 444-449, 2013.

[22] K. R. Sheth and B. M. Clary, "Management of hepatic metastases from colorectal cancer," Clinics in Colon and Rectal Surgery, vol. 18, no. 3, pp. 215-223, 2005.

[23] M. Jung, A. Holmqvist, X. Sun, and M. Albertsson, "A clinical study of metastasized rectal cancer treatment: assessing a multimodal approach," Medical Oncology, vol. 31, no. 3, p. 839, 2014.

[24] B. Nordlinger, H. Sorbye, B. Glimelius et al., "Perioperative chemotherapy with FOLFOX4 and surgery versus surgery alone for resectable liver metastases from colorectal cancer (EORTC Intergroup trial 40983): a randomised controlled trial," The Lancet, vol. 371, no. 9617, pp. 1007-1016, 2008.

[25] A. Grothey, M. M. Sugrue, D. M. Purdie et al., "Bevacizumab beyond first progression is associated with prolonged overall survival in metastatic colorectal cancer: results from a large observational cohort study (BRiTE)," Journal of Clinical Oncology, vol. 26, no. 33, pp. 5326-5334, 2008.

[26] M. R. Weiser, W. R. Jarnagin, and L. B. Saltz, "Colorectal cancer patients with oligometastatic liver disease: what is the optimal approach?” Oncology (Williston Park), vol. 27, pp. 1074-1078, 2013.

[27] G. P. Kanas, A. Taylor, J. N. Primrose et al., "Survival after liver resection in metastatic colorectal cancer: Review and metaanalysis of prognostic factors," Journal of Clinical Epidemiology, vol. 4, no. 1, pp. 283-301, 2012.

[28] K. T. Liu, J. F. Wan, J. Zhu et al., "Role of pelvic radiotherapy for locally advanced rectal cancer and synchronous unresectable distant metastases," Cancer Radiothérapie, vol. 20, no. 8, pp. 805-810, 2016.

[29] T. A. Aloia, J.-N. Vauthey, E. M. Loyer et al., "Solitary colorectal liver metastasis: Resection determines outcome," JAMA Surgery, vol. 141, no. 5, pp. 460-467, 2006.

[30] T. Mitin, C. K. Enestvedt, and C. R. Thomas Jr., "Management of oligometastatic rectal cancer: is liver first?" World Journal of Gastrointestinal Oncology, vol. 6, no. 2, pp. 201-207, 2015.

[31] H. Hur, Y. T. Ko, B. S. Min et al., "Comparative study of resection and radiofrequency ablation in the treatment of solitary colorectal liver metastases," The American Journal of Surgery, vol. 197, no. 6, pp. 728-736, 2009.
[32] S. Ahmed, A. Leis, S. Chandra-Kanthan et al., "Surgical management of the primary tumor in stage IV colorectal cancer: A confirmatory retrospective cohort study," Journal of Cancer, vol. 7, no. 7, pp. 837-845, 2016.

[33] S. Ahmed, A. Leis, A. Fields et al., "Survival impact of surgical resection of primary tumor in patients with stage IV colorectal cancer: Results from a large population-based cohort study," Cancer, vol. 120, no. 5, pp. 683-691, 2014.

[34] S. Ahmed, A. Fields, P. Pahwa et al., "Surgical resection of primary tumor in asymptomatic or minimally symptomatic patients with stage IV colorectal cancer: a canadian province experience," Clinical Colorectal Cancer, vol. 14, no. 4, pp. e41e47, 2015.

[35] W.-S. Lee, S. H. Yun, H.-K. Chun et al., "Clinical outcomes of hepatic resection and radiofrequency ablation in patients with solitary colorectal liver metastasis," Journal of Clinical Gastroenterology, vol. 42, no. 8, pp. 945-949, 2008.

[36] A. Cucchetti, A. Ferrero, M. Cescon et al., "Cure model survival analysis after hepatic resection for colorectal liver metastases," Annals of Surgical Oncology, vol. 22, no. 6, pp. 1908-1914, 2015.

[37] G. Tsoulfas, "Surgical treatment of hepatic metastases from colorectal cancer," World Journal of Gastrointestinal Oncology, vol. 3, no. 1, pp. 1-9, 2011.

[38] F. G. Fernandez, J. A. Drebin, D. C. Linehan et al., "Five-year survival after resection of hepatic metastases from colorectal cancer in patients screened by positron emission tomography with F-18 fluorodeoxyglucose (FDG-PET)," Annals of Surgery, vol. 240, no. 3, pp. 438-450, 2004.

[39] E. K. Abdalla, J.-N. Vauthey, L. M. Ellis et al., "Recurrence and outcomes following hepatic resection, radiofrequency ablation, and combined resection/ablation for colorectal liver metastases," Annals of Surgery, vol. 239, no. 6, pp. 818-827, 2004.

[40] L. C. Cummings, J. D. Payes, and G. S. Cooper, "Survival after hepatic resection in metastatic colorectal cancer: A populationbased study," Cancer, vol. 109, no. 4, pp. 718-726, 2007.

[41] J. Scheele, R. Stang, A. Altendorf-Hofmann, and M. Paul, "Resection of colorectal liver metastases," World Journal of Surgery, vol. 19, no. 1, pp. 59-71, 1995.

[42] E. J. Morris, D. Forman, J. D. Thomas et al., "Surgical management and outcomes of colorectal cancer liver metastases," British Journal of Surgery, vol. 97, no. 11, p. 1110, 2010.

[43] A. C. Wei, P. D. Greig, D. Grant, B. Taylor, B. Langer, and S. Gallinger, "Survival after hepatic resection for colorectal metastases: a 10-year experience," Annals of Surgical Oncology, vol. 13, no. 5, pp. 668-676, 2006.

[44] M. Rees, P. P. Tekkis, F. K. S. Welsh, T. O’Rourke, and T. G. John, "Evaluation of long-term survival after hepatic resection for metastatic colorectal cancer: A multifactorial model of 929 patients," Annals of Surgery, vol. 247, no. 1, pp. 125-135, 2008.

[45] C. Platell, S. Ng, A. O'Bichere, and N. Tebbutt, "Changing management and survival in patients with stage IV colorectal cancer," Diseases of the Colon \& Rectum, vol. 54, no. 2, pp. 214219, 2011.

[46] P. C. Simmonds, J. N. Primrose, J. L. Colquitt, O. J. Garden, G. J. Poston, and M. Rees, "Surgical resection of hepatic metastases from colorectal cancer: A systematic review of published studies," British Journal of Cancer, vol. 94, no. 7, pp. 982-999, 2006.

[47] J. S. Tomlinson, W. R. Jarnagin, R. P. DeMatteo et al., "Actual 10 -year survival after resection of colorectal liver metastases defines cure," Journal of Clinical Oncology, vol. 25, no. 29, pp. 4575-4580, 2007. 
[48] R. Sauer, H. Becker, W. Hohenberger et al., "Preoperative versus postoperative chemoradiotherapy for rectal cancer," The New England Journal of Medicine, vol. 351, no. 17, pp. 1731-1810, 2004.

[49] R. Sauer, T. Liersch, and S. Merkel, "Preoperative versus postoperative chemoradiotherapy for locally advanced rectal cancer: results of the German CAO/ARO/AIO-94 randomized phase III trial after a median follow-up of 11 years," Journal of Clinical Oncology, vol. 30, no. 16, pp. 1926-1933, 2012.

[50] Colorectal Cancer Collaborative Group, "Adjuvant radiotherapy for rectal cancer: a systematic overview of 8507 patients from 22 randomised trials," The Lancet, vol. 358, no. 9290, pp. 1291-1304, 2001.

[51] K. Bujko, M. P. Nowacki, A. Nasierowska-Guttmejer, W. Michalski, M. Bebenek, and M. Kryj, "Long-term results of a randomized trial comparing preoperative short-course radiotherapy with preoperative conventionally fractionated chemoradiation for rectal cancer," British Journal of Surgery, vol. 93, no. 10, pp. 1215-1223, 2006.

[52] K. Bujko, M. P. Nowacki, A. Nasierowska-Guttmejer et al., "Sphincter preservation following preoperative radiotherapy for rectal cancer: Report of a randomised trial comparing short-term radiotherapy vs. conventionally fractionated radiochemotherapy," Radiotherapy \& Oncology, vol. 72, no. 1, pp. 15-24, 2004.

[53] L. Pietrzak, K. Bujko, M. P. Nowacki et al., "Quality of life, anorectal and sexual functions after preoperative radiotherapy for rectal cancer: Report of a randomised trial," Radiotherapy \& Oncology, vol. 84, no. 3, pp. 217-225, 2007.

[54] S. Y. Ngan, B. Burmeister, R. J. Fisher et al., "Randomized trial of short-course radiotherapy versus long-course chemoradiation comparing rates of local recurrence in patients with $\mathrm{t} 3$ rectal cancer: trans-tasman radiation oncology group trial 01.04," Journal of Clinical Oncology, vol. 30, no. 31, pp. 3827-3833, 2012.

[55] S.-A. McLachlan, R. J. Fisher, J. Zalcberg et al., "The impact on health-related quality of life in the first 12 months: A randomised comparison of preoperative short-course radiation versus long-course chemoradiation for T3 rectal cancer (TransTasman Radiation Oncology Group Trial 01.04)," European Journal of Cancer, vol. 55, pp. 15-26, 2016.

[56] K. Chen, G. Xie, Q. Zhang, Y. Shen, and T. Zhou, "Comparison of short-course with long-course preoperative neoadjuvant therapy for rectal cancer: A meta-analysis," Journal of Cancer Research and Therapeutics, vol. 14, no. 8, pp. S224-S231, 2018.

[57] S. W. Dutta, C. E. Alonso, T. C. Jones, M. R. Waddle, E. Janowski, and D. M. Trifiletti, "Short-course versus long-course neoadjuvant therapy for non-metastatic rectal cancer: patterns of care and outcomes from the national cancer database," Clinical Colorectal Cancer, vol. 17, no. 4, pp. 297-306, 2018.

[58] B. Glimelius, T. Å. Myklebust, K. Lundqvist, A. Wibe, and M. G. Guren, "Two countries - Two treatment strategies for rectal cancer," Radiotherapy \& Oncology, vol. 121, no. 3, pp. 357-363, 2016.

[59] R. Glynne-Jones, L. Wyrwicz, E. Tiret et al., "Rectal cancer: ESMO Clinical Practice Guidelines for diagnosis, treatment and follow-up," Annals of Oncology, vol. 28, pp. iv22-iv40, 2017.

[60] M. Aghili, S. Sotoudeh, R. Ghalehtaki et al., "Preoperative short course radiotherapy with concurrent and consolidation chemotherapies followed by delayed surgery in locally advanced rectal cancer: Preliminary results," Radiation Oncology Journal, vol. 36, no. 1, pp. 17-24, 2018.

[61] J. Erlandsson, T. Holm, D. Pettersson et al., "Optimal fractionation of preoperative radiotherapy and timing to surgery for rectal cancer (Stockholm III): a multicentre, randomised, nonblinded, phase 3, non-inferiority trial," The Lancet Oncology, vol. 18, no. 3, pp. 336-346, 2017.

[62] K. Bujko and R. Sopyło, "Short-course radiotherapy with delayed surgery for rectal cancer: a third option," The Lancet Oncology, vol. 18, no. 3, pp. 275-276, 2017.

[63] Z. Sun, M. A. Adam, J. Kim, M. Shenoi, J. Migaly, and C. R. Mantyh, "Optimal timing to surgery after neoadjuvant chemoradiotherapy for locally advanced rectal cancer," Journal of the American College of Surgeons, vol. 222, no. 4, pp. 367-374, 2016.

[64] D. Pettersson, E. Lörinc, T. Holm et al., "Tumour regression in the randomized Stockholm III Trial of radiotherapy regimens for rectal cancer," British Journal of Surgery, vol. 102, no. 8, pp. 972-978, 2015.

[65] C. P. Probst, A. Z. Becerra, C. T. Aquina et al., "Extended intervals after neoadjuvant therapy in locally advanced rectal cancer: the key to improved tumor response and potential organ preservation," Journal of the American College of Surgeons, vol. 221, no. 2, pp. 430-440, 2015.

[66] E. Kaytan-Saglam, E. Balik, S. Saglam et al., "Delayed versus immediate surgery following short-course neoadjuvant radiotherapy in resectable $(\mathrm{T} 3 \mathrm{~N} 0 / \mathrm{N}+)$ rectal cancer," Journal of Cancer Research and Clinical Oncology, vol. 143, no. 8, pp. 15971603, 2017.

[67] W.-G. Zeng, Z.-X. Zhou, J.-W. Liang et al., "Impact of interval between neoadjuvant chemoradiotherapy and surgery for rectal cancer on surgical and oncologic outcome," Journal of Surgical Oncology, vol. 110, no. 4, pp. 463-467, 2014.

[68] J. Garcia-Aguilar, D. D. Smith, K. Avila, E. K. Bergsland, P. Chu, and R. M. Krieg, "Optimal timing of surgery after chemoradiation for advanced rectal cancer: preliminary results of a multicenter, nonrandomized phase II prospective trial," Annals of Surgery, vol. 254, no. 1, pp. 97-102, 2011.

[69] T. Latkauskas, H. Pauzas, I. Gineikiene et al., "Initial results of a randomized controlled trial comparing clinical and pathological downstaging of rectal cancer after preoperative shortcourse radiotherapy or long-term chemoradiotherapy, both with delayed surgery," Colorectal Disease, vol. 14, no. 3, pp. 294298, 2012.

[70] E. Kapiteijn, C. A. M. Marijnen, I. D. Nagtegaal et al., "Preoperative radiotherapy combined with total mesorectal excision for resectable rectal cancer," The New England Journal of Medicine, vol. 345, no. 9, pp. 638-646, 2001.

[71] Q. Yang, F. Liao, Y. Huang et al., "Longterm effects of palliative local treatment of incurable metastatic lesions in colorectal cancer patients," Oncotarget, vol. 7, no. 15, pp. 21034-21045, 2016.

[72] F. Deodato, V. Picardi, A. Guido et al., "Palliative short-course radiation therapy in rectal cancer: a phase 2 study," International Journal of Radiation Oncology Biology Physics, vol. 95, no. 4, pp. 1184-1190, 2016.

[73] S. J. Shin, H. I. Yoon, N. K. Kim et al., "Upfront systemic chemotherapy and preoperative short-course radiotherapy with delayed surgery for locally advanced rectal cancer with distant metastases," Journal of Radiation Oncology, vol. 6, no. 1, article 99, 2011.

[74] L. Resende Salgado, H. Hsu, and K. Du, "Outcomes of rectal cancer with liver oligometastases," Journal of Gastrointestinal Oncology, vol. 5, no. 6, pp. 414-420, 2014.

[75] H. Salvador-Rosés, S. López-Ben, M. Casellas-Robert et al., "Oncological strategies for locally advanced rectal cancer with 
synchronous liver metastases, interval strategy versus rectum first strategy: a comparison of short-term outcomes," Clinical and Translational Oncology, vol. 20, no. 8, pp. 1018-1025, 2018.

[76] E. B. Holliday, A. Hunt, Y. Nancy You et al., "Short course radiation as a component of definitive multidisciplinary treatment for select patients with metastatic rectal adenocarcinoma," Journal of Gastrointestinal Oncology, vol. 8, no. 6, pp. 990-997, 2017.

[77] S. Markovina, F. Youssef, A. Roy et al., "Improved metastasisand disease-free survival with preoperative sequential shortcourse radiation therapy and folfox chemotherapy for rectal cancer compared with neoadjuvant long-course chemoradiotherapy: results of a matched pair analysis," International Journal of Radiation Oncology Biology Physics, vol. 99, no. 2, pp. 417426, 2017.

[78] T. H. Van Dijk, K. Tamas, J. C. Beukema et al., "Evaluation of short-course radiotherapy followed by neoadjuvant bevacizumab, capecitabine, and oxaliplatin and subsequent radical surgical treatment in primary stage IV rectal cancer," Annals of Oncology, vol. 24, no. 7, pp. 1762-1769, 2013.

[79] C. Bisschop, T. H. van Dijk, J. C. Beukema et al., "Shortcourse radiotherapy followed by neoadjuvant bevacizumab, capecitabine, and oxaliplatin and subsequent radical treatment in primary stage iv rectal cancer: long-term results of a phase II study," Annals of Surgical Oncology, vol. 24, no. 9, pp. 2632-2638, 2017.

[80] T. Bird, M. Michael, M. Bressel et al., "FOLFOX and intensified split-course chemoradiation as initial treatment for rectal cancer with synchronous metastases," Acta Oncologica, vol. 56, no. 5, pp. 646-652, 2017.

[81] K. H. Kim, S. J. Shin, M. S. Cho et al., "A phase II study of preoperative mFOLFOX6 with short-course radiotherapy in patients with locally advanced rectal cancer and liver-only metastasis," Radiotherapy \& Oncology, vol. 118, no. 2, pp. 369374, 2016.

[82] H. Cho, J. E. Kim, K. Kim et al., "Phase II Study of Preoperative Capecitabine and Oxaliplatin-based Intensified Chemoradiotherapy With or Without Induction Chemotherapy in Patients With Locally Advanced Rectal Cancer and Synchronous Liverlimited Resectable Metastases," American Journal of Clinical Oncology, vol. 39, no. 6, pp. 623-629, 2016.

[83] H. I. Yoon, W. S. Koom, T. H. Kim et al., "Upfront systemic chemotherapy and short-course radiotherapy with delayed surgery for locally advanced rectal cancer with distant metastases: outcomes, compliance, and favorable prognostic factors," PLoS ONE, vol. 11, no. 8, Article ID e0161475, 2016.

[84] K. J. Labori, M. G. Guren, K. W. Brudvik et al., "Resection of synchronous liver metastases between radiotherapy and definitive surgery for locally advanced rectal cancer: shortterm surgical outcomes, overall survival and recurrence-free survival," Colorectal Disease, vol. 19, no. 8, pp. 731-738, 2017.

[85] C. H. Crane, N. A. Janjan, J. L. Abbruzzese et al., "Effective pelvic symptom control using initial chemoradiation without colostomy in metastatic rectal cancer," International Journal of Radiation Oncology • Biology • Physics, vol. 49, no. 1, pp. 107-116, 2001.

[86] S. H. Bae, W. Park, D. H. Choi et al., "Palliative radiotherapy in patients with a symptomatic pelvic mass of metastatic colorectal cancer," Journal of Radiation Oncology, vol. 6, no. 1, p. 52, 2011.
[87] D. Tyc-Szczepaniak, L. Wyrwicz, L. Kepka et al., "Palliative radiotherapy and chemotherapy instead of surgery in symptomatic rectal cancer with synchronous unresectable metastases: A phase II study," Annals of Oncology, vol. 24, no. 11, Article ID mdt363, pp. 2829-2834, 2013.

[88] I. Craven, J. Haselden, K. E. Miller, G. V. Miller, I. Bradford, and D. Sebag-Montefiore, "Omission of concurrent chemoradiation after a response to neoadjuvant chemotherapy in locally advanced rectal cancer with a synchronous liver metastasis: a note of caution," British Journal of Radiology, vol. 80, no. 958, pp. e257-e259, 2007.

[89] R. J. Cassidy, Y. Liu, K. Patel et al., "Can we eliminate neoadjuvant chemoradiotherapy in favor of neoadjuvant multiagent chemotherapy for select stage II/III rectal adenocarcinomas: Analysis of the National Cancer Data base," Cancer, vol. 123, no. 5, pp. 783-793, 2017.

[90] Y. H. Sada, H. S. Tran Cao, G. J. Chang et al., "Prognostic value of neoadjuvant treatment response in locally advanced rectal cancer," Journal of Surgical Research, vol. 226, pp. 15-23, 2018.

[91] C. C. Fossum, J. Y. Alabbad, L. B. Romak et al., "The role of neoadjuvant radiotherapy for locally-advanced rectal cancer with resectable synchronous metastasis," Journal of Gastrointestinal Oncology, vol. 8, no. 4, pp. 650-658, 2017.

[92] T. Takada, S. Tsutsumi, R. Takahashi et al., "Control of primary lesions using resection or radiotherapy can improve the prognosis of metastatic colorectal cancer patients," Journal of Surgical Oncology, vol. 114, no. 1, pp. 75-79, 2016.

[93] C.-H. Zhang, Y.-B. Pan, Q.-W. Zhang et al., "The influence of local therapy on the survival of patients with metastatic rectal cancer: a population-based, propensity-matched study," Journal of Cancer Research and Clinical Oncology, vol. 143, no. 9, pp. 1891-1903, 2017.

[94] M. G. Cameron, C. Kersten, I. Vistad et al., "Palliative pelvic radiotherapy of symptomatic incurable rectal cancer - a systematic review," Acta Oncologica, vol. 53, no. 2, pp. 164-173, 2014.

[95] M. Buwenge, L. Giaccherini, A. Guido et al., "Radiotherapy for the primary tumor in patients with metastatic rectal cancer," Current Colorectal Cancer Reports, vol. 13, no. 3, pp. 250-256, 2017.

[96] R. Adam, A. de Gramont, J. Figueras et al., "Managing synchronous liver metastases from colorectal cancer: A multidisciplinary international consensus," Cancer Treatment Reviews, vol. 41, no. 9, pp. 729-741, 2015.

[97] Z. Yin, C. Liu, Y. Chen et al., "Timing of hepatectomy in resectable synchronous colorectal liver metastases (SCRLM): Simultaneous or delayed?" Hepatology, vol. 57, no. 6, pp. 23462357, 2013.

[98] T. Ruers, C. Punt, F. Van coevorden et al., "Radiofrequency ablation combined with systemic treatment versus systemic treatment alone in patients with non-resectable colorectal liver metastases: A randomized eortc intergroup phase ii study (EORTC 40004)," Annals of Oncology, vol. 23, no. 10, pp. 26192626, 2012.

[99] S. B. Edge and C. C. Compton, "The american joint committee on cancer: the 7th edition of the AJCC cancer staging manual and the future of TNM," Annals of Surgical Oncology, vol. 17, no. 6, pp. 1471-1474, 2010.

[100] A. K. Siriwardena, J. M. Mason, S. Mullamitha, H. C. Hancock, and S. Jegatheeswaran, "Management of colorectal cancer presenting with synchronous liver metastases," Nature Reviews Clinical Oncology, vol. 11, no. 8, pp. 446-459, 2014. 
[101] L. J. M. Mekenkamp, M. Koopman, S. Teerenstra et al., "Clinicopathological features and outcome in advanced colorectal cancer patients with synchronous vs metachronous metastases," British Journal of Cancer, vol. 103, no. 2, pp. 159-164, 2010.

[102] R. Adam, A. Frilling, D. Elias et al., "Liver resection of colorectal metastases in elderly patients," British Journal of Surgery, vol. 97, no. 3, pp. 366-376, 2010.

[103] F. Ghiringhelli, A. Hennequin, A. Drouillard, C. Lepage, J. Faivre, and A.-M. Bouvier, "Epidemiology and prognosis of synchronous and metachronous colon cancer metastases: A French population-based study," Digestive and Liver Disease, vol. 46, no. 9, pp. 854-858, 2014.

[104] I. Bartolini, M. N. Ringressi, F. Melli et al., "Analysis of prognostic factors for resected synchronous and metachronous liver metastases from colorectal cancer," Gastroenterology Research and Practice, vol. 2018, Article ID 5353727, 14 pages, 2018.

[105] M. D’Hondt, V. Lucidi, K. Vermeiren, B. Van Den Bossche, V. Donckier, and G. Sergeant, "The interval approach: an adaptation of the liver-first approach to treat synchronous liver metastases from rectal cancer," World Journal of Surgical Oncology, vol. 15, no. 1, p. 54, 2017.

[106] S. Demiral, M. Beyzadeoglu, O. Sager et al., "Evaluation of transforming growth factor- $\beta 2$ for radiation-induced diarrhea after pelvic Radiotherapy," TUMORI, vol.101, no. 5, pp. 474-477, 2015. 


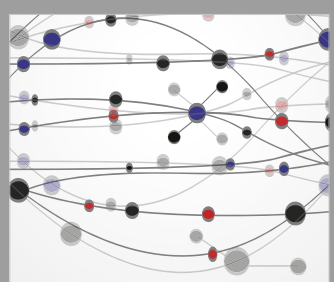

The Scientific World Journal
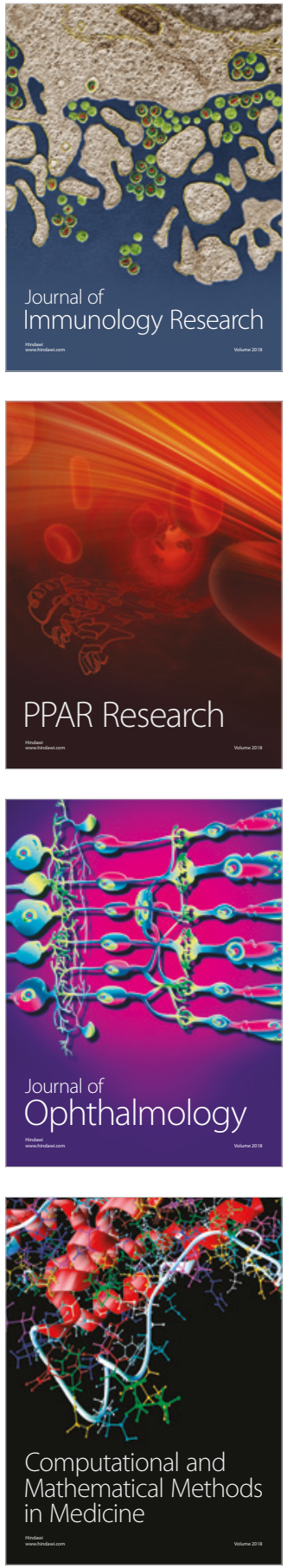

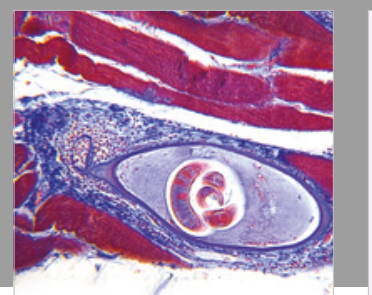

Gastroenterology Research and Practice

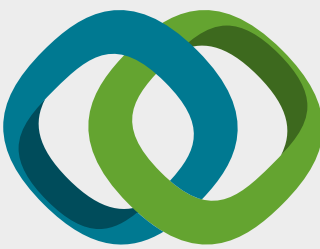

\section{Hindawi}

Submit your manuscripts at

www.hindawi.com
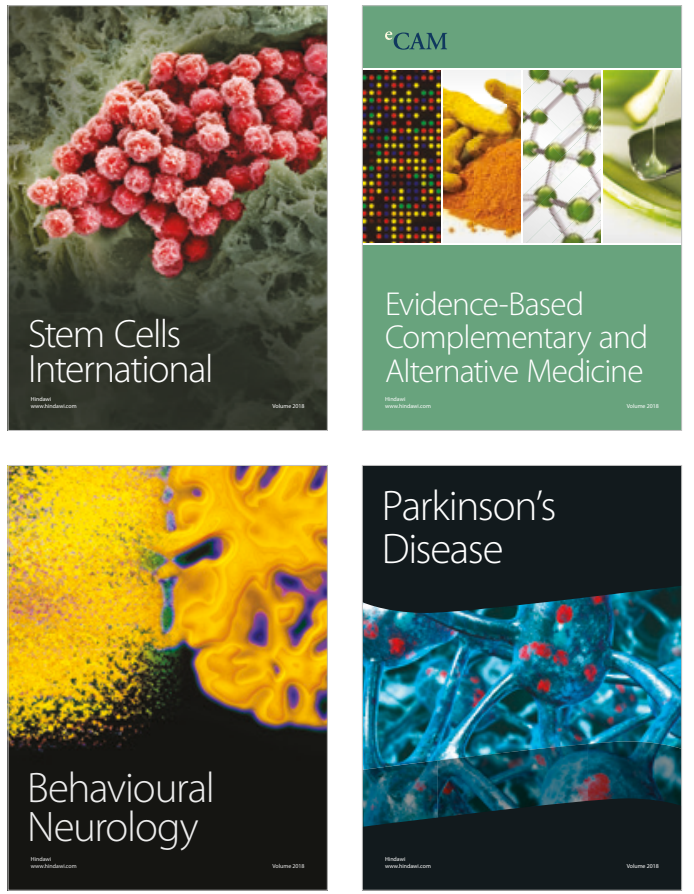

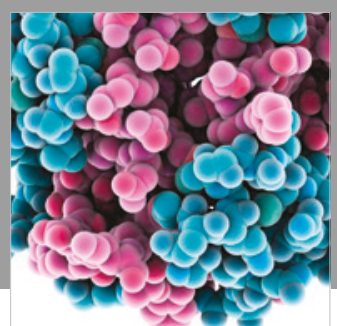

ournal of

Diabetes Research

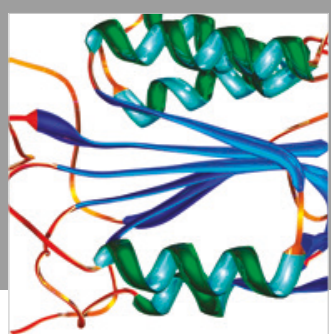

Disease Markers
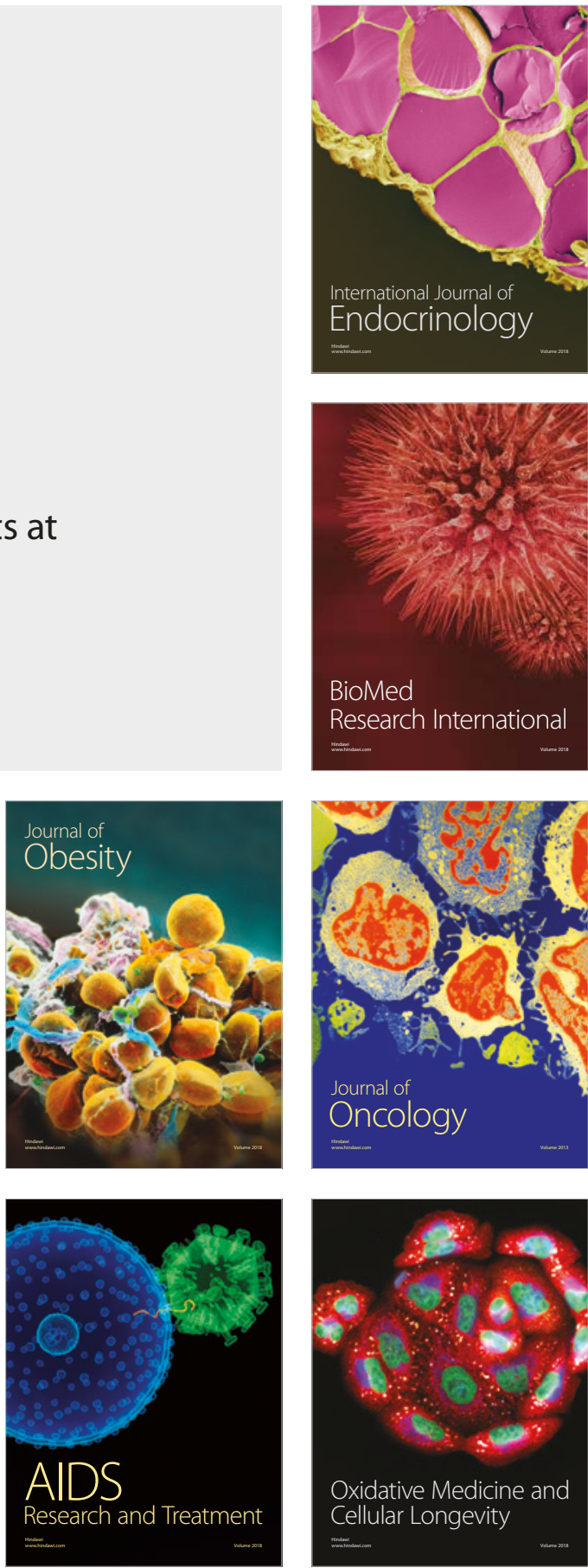